\title{
Author Correction: The climate mitigation opportunity behind global power transmission and distribution
}

Kavita Surana (iD and Sarah M. Jordaan (iD

Correction to: Nature Climate Change https://doi.org/10.1038/s41558-019-0544-3, published online 12 August 2019.

In the version of this Letter originally published, the authors mistakenly omitted the results showing the estimate of average potential reductions in compensatory emissions from reducing aggregate T\&D losses in India in Fig. 3c. Consequently, the range '>80-160' in Fig. $3 \mathrm{c}$ was incorrect, as it omitted the high value for India in the map only; it should have been ' $>80-165$ '. The original results and conclusions are unaffected by this error. Additionally, in Figs. 2a,c and 3a,c, countries shown in white should have instead been crosshatched to indicate that no data were available. The online versions of the Letter have been corrected.

\section{Original}

c

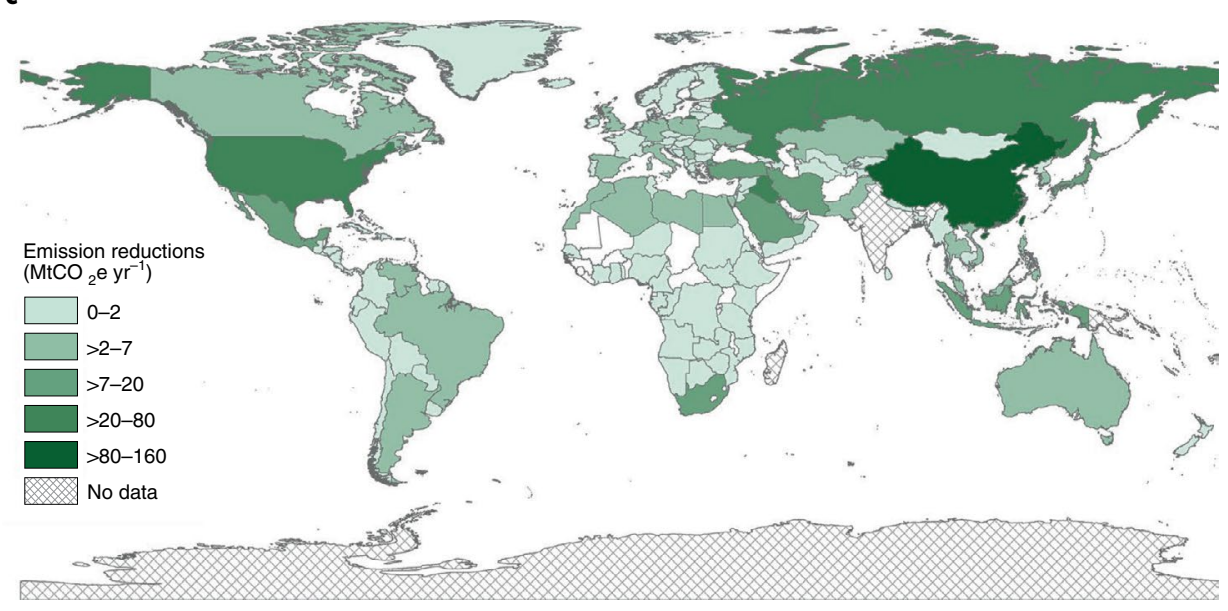

Corrected

c

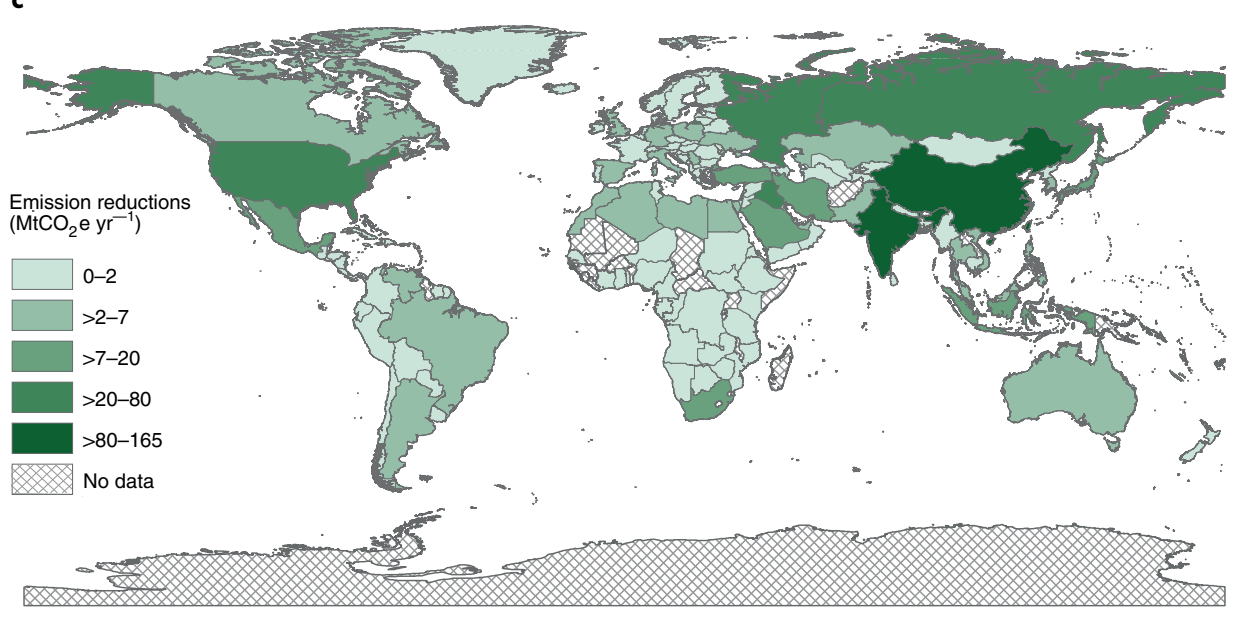

Fig. 3c | Original and Corrected.

Published online: 29 June 2021

https://doi.org/10.1038/s41558-021-01091-w

( The Author(s), under exclusive licence to Springer Nature Limited 2021 